\title{
Optimal Design of PSS on SMIB Using Particle Swarm Optimization
}

\author{
Muhammad Ruswandi Djalal ${ }^{1, *, a}$, Makmur Saini ${ }^{1, b}$, A.M.Shiddiq Yunus ${ }^{1, \mathrm{c}}$ \\ ${ }^{1}$ Department of Mechanical Engineering, State Polytechnic of Ujung Pandang, Jl Perintis Kemerdekaan KM.10, Makassar, 90245, \\ Indonesia \\ a, ${ }^{*}$ wandi@poliupg.ac.id (Corresponding Author) \\ bmakmur.saini@poliupg.ac.id \\ cshiddiq@poliupg.ac.id
}

\begin{abstract}
Dynamic disturbances in the power system are caused by sudden changes in load. This condition causes the stability of the generator to be disturbed, such as the emergence of oscillations in the generator in the form of oscillations of frequency and rotor angle. Power System Stabilizer (PSS) is an additional control that can increase generator stability. To get optimal PSS performance, proper tuning of PSS parameters is needed. Optimal performance of PSS can cause the frequency response and angle of the SMIB rotor to be stable. In this study, PSO is used for optimization of PSS parameters. PSS is able to provide stability so that overshoot oscillations can be suppressed, as well as faster settling time performance for the system to reach steady state conditions. To test the reliability of the SMIB, a case study of adding and subtracting loads was used.
\end{abstract}

Keywords: PSO, PSS, SMIB, Settling Time, Overshoot.

\section{Introduction}

For stability analysis, the torque change due to the governor response is ignored, because the governor response is slower than the excitation device, therefore, that the control is on the excitation. The addition of excitation is not able to manage stability of the system in low-frequency oscillations condition. [1].

Additional controls such as Power System Stabilizer (PSS) are needed because lower frequencies can spread to oscillations between areas. PSS can be an additional control on generator excitation, PSS provides additional damping on generator excitation [2], [3]. PSS can also serve to reduce local or global oscillations in generators [4], [5]. This research uses a case study on Single Machine Infinite Bus (SMIB). SMIB is one part of the electric power system which consists of several generators connected to an unlimited bus [6], [7].

Particle Swarm Optimization is one of the artificial intelligence methods that is widely used in solving power system optimization problems. The way PSO works is like a flock of birds or fish in finding food sources where each individual is called a particle and the population is called a swarm (colony). PSO is initialized with a set of particles as candidate solutions at random positions. Each particle is given an initial position and initial velocity. PSO has advantages such as fast and accurate optimization speed. Several conventional PSS applications in the SMIB control system include [8], [9]. Meanwhile, the optimization of intelligent algorithms includes [10] discussing the application of the bat algorithm for tuning PID and PSS parameters. Ref [11] discusses the application of the Ant Colony algorithm for tuning PID and PSS parameters. For this reason, in this study the PSO method was used for optimization of PSS control. System analysis by comparing the simulation results of the system without control and with SMIB-PSS.

\section{System Modeling}

a. Synchronous Machine Linear Modeling

The machine modeling is shown in Figure 1.

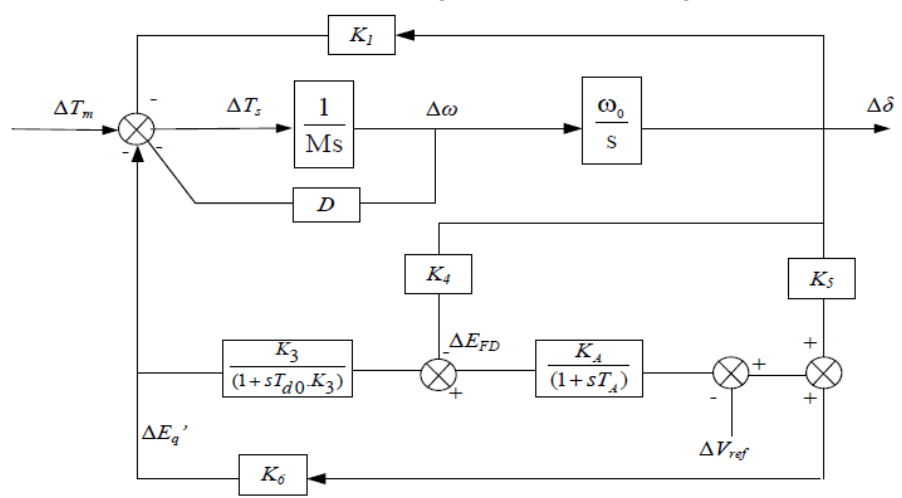

Figure 1. Synchronous Machine Linear Model

\section{b. Excitation Modeling}

Excitation functions to regulate voltage, current and power factor [2]. Excitation modeling is shown in Figure 2 below [12]. 


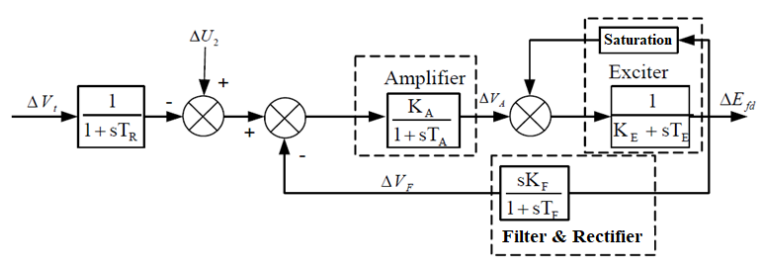

Figure 2. Block Diagram of Excitation

\section{c. Governor Modeling}

The modeling of the governor is shown in Figure 3 [12].

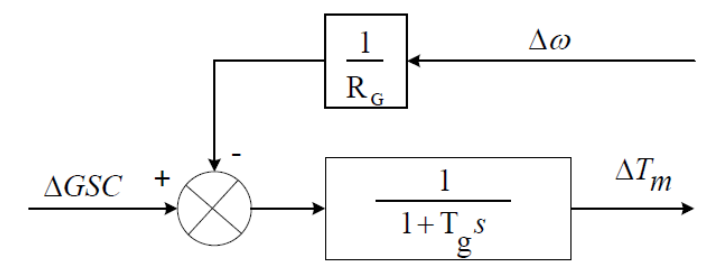

Figure 3. Governor Model

\section{d. Turbine Modeling}

Turbine modeling is shown in Figure 4 [13].

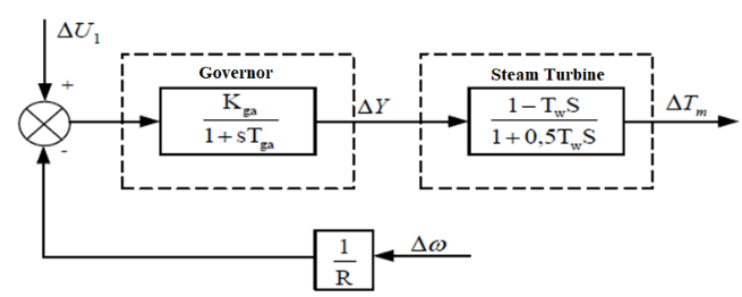

Figure 4. Turbine Model

e. Single Machine Infinite Bus (SMIB) Modeling

SMIB modeling is shown in figure 5 [14].

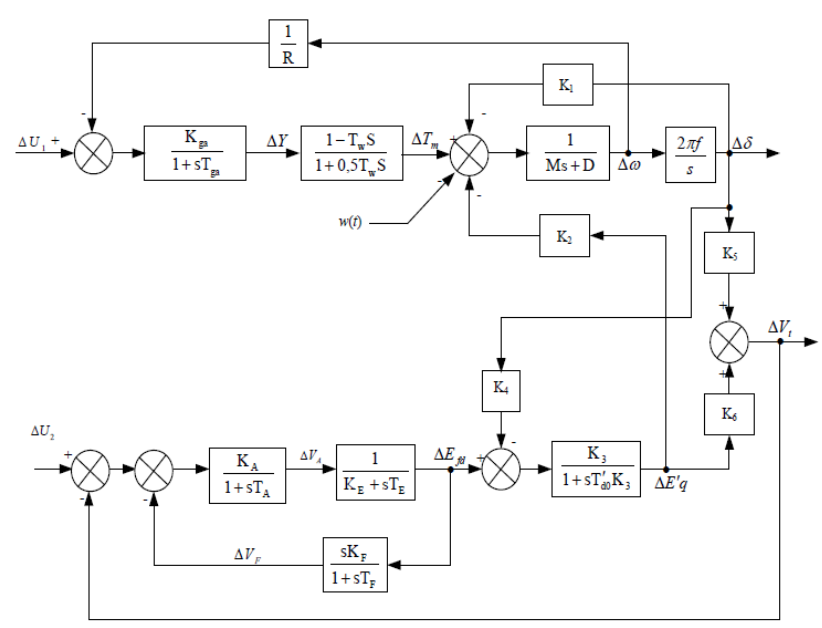

Figure 5. SMIB Model

\section{f. Power System Stabilizer (PSS) Modeling}

PSS serves to provide additional damping to the generator. PSS model is shown in Figure 6.

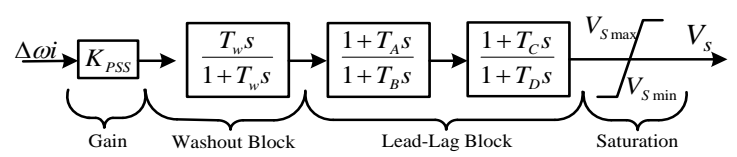

Figure 6. PSS Modeling

\section{Particle Swarm Optimization (PSO)}

PSO is a population algorithm technique. The PSO process starts by spreading the particle population in an optimization problem. With implementing the objective as an evaluation function for each particle, it will be known the effect of the position of each particle on the optimum value of the target. The different objective used for each problem. From the results of this evaluation, the local best position and the good global position will be obtained respectively pbest $t_{i}=\left(p_{i l}, p_{i l}\right.$, $\left.\ldots, p_{i d}\right)$ and pbest $_{g}=$ gbest $=\left(p_{g l}, p_{g 2}, \ldots, p_{g d}\right)$, where $\mathrm{g}$ is the particle in the position with the optimum yield function. Each particle will try to modify its position using the velocity function between the pbest and gbest distances. The velocity improvement function (velocity update) and the position update function of each particle are written in the following equation..

$$
\begin{gathered}
v_{i}^{k+1}=w^{k} v_{i}+c 1 r 1\left(p \text { Best }_{i}-x_{i}^{k}\right)+c 2 r 2\left(g B e s t-x_{i}^{k}\right) \\
x_{i}^{k+1}=x_{i}+v_{i}^{k+1}
\end{gathered}
$$

Where,

$$
\begin{array}{ll}
k & =\text { Iteration } \\
v_{i} & =\text { Particle speed } \\
x_{i} & =\text { Position Particle } \\
c 1 & =\text { Acc. } \text { constant } 1 \\
c 2 & =\text { Acc. constant } 2 \\
r 1 & =\text { Random constant } 1 \\
r 2 & =\text { Random constant } 2 \\
p B e s t & =\text { Best Local particle position } \\
\text { gBest } & =\text { Best Global particle position }
\end{array}
$$

In the equation, it is written that there is the use of the $w^{k}$ variable which is a weighing function. The purpose of placing the weight function is to regulate the local and global exploration carried out by the particle for each iteration. It should be explained earlier that the amount of movement carried out by the particle is determined by the number of iterations to be applied. The weight improvement function is written in the following equation, 


$$
w^{k}=\left(w_{\max }-w_{\min }\right) \times\left(\frac{\text { iter }_{\max }-i t e r^{k}}{\text { iter }_{\max }}\right)+w_{\min }
$$

Where,

$$
\begin{array}{ll}
w & =\text { weight } \\
w_{\max } & =\text { Maximum weighing value } \\
w_{\min } & =\text { Minimum weighing value } \\
\text { iter }_{\max } & =\text { Maximum iteration } \\
\text { iter } & =\text { Iteration }
\end{array}
$$

The PSO and PSS parameters used are shown in Tables 1 and 2 below.

Table 1. PSO Parameters

\begin{tabular}{|l|l|}
\hline Particles & 30 \\
\hline Iteration & 50 \\
\hline Variables & 3 \\
\hline Social Constant (C2) & 2 \\
\hline Cognitive Constant (C1) & 2 \\
\hline Moment Inersia (W) & 0.9 \\
\hline
\end{tabular}

Table 2. Constraint of PSS Parameters [3]

\begin{tabular}{|l|l|c|c|}
\hline No & Parameter & Lower & Upper \\
\hline 1 & Kpss & 10 & 50 \\
\hline 2 & T1 & 0 & 0.05 \\
\hline 3 & T2 & 0 & 0.05 \\
\hline 4 & T3 & 0 & 1 \\
\hline 5 & T4 & 0 & 2 \\
\hline 6 & Tw & \multicolumn{2}{|c|}{10} \\
\hline
\end{tabular}

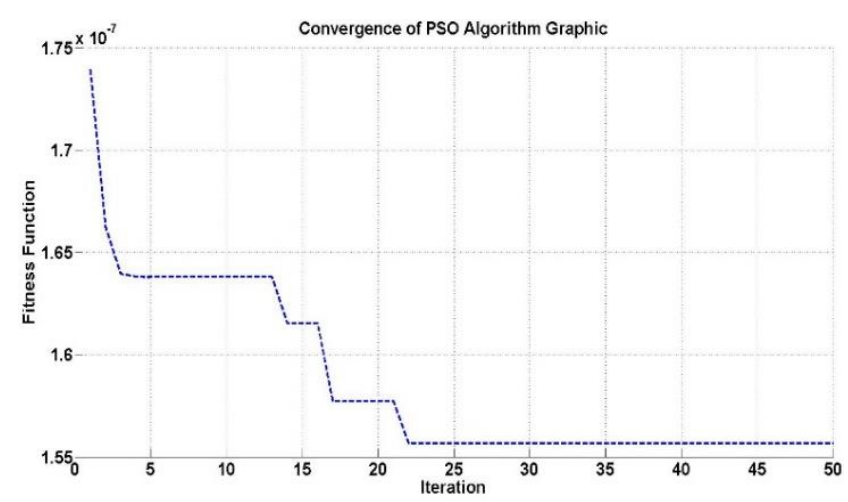

Figure 7. PSO convergence graph

Figure 7 shows the optimization process for PSS parameters. The calculation process converges on the 22nd iteration. PSS optimization results is shown in table 3 .

Table 3. Tuning Results of PSS Parameter with PSO

\begin{tabular}{|l|l|c|c|}
\hline No & Parameter & PSS & PSS-PSO \\
\hline 1 & $\mathrm{~K}_{\mathrm{pss}}$ & 30.9788 & 50.6243 \\
\hline 2 & $\mathrm{~T}_{1}$ & 1.1687 & 0.0601 \\
\hline 3 & $\mathrm{~T}_{2}$ & 1.1292 & 0.0236 \\
\hline 4 & $\mathrm{~T}_{3}$ & 1.3008 & 1.2051 \\
\hline
\end{tabular}

\begin{tabular}{|l|l|l|l|}
\hline 5 & $\mathrm{~T}_{4}$ & 1.1590 & 6.1021 \\
\hline 6 & $\mathrm{TW}$ & \multicolumn{2}{|c|}{2} \\
\hline
\end{tabular}

\section{Results and Analysis}

Analysis of the frequency and angle of the rotor will be analyzed. With several SMIB system schemes such as systems without control and systems with control of Power System Stabilizer. PSS gain is optimized using Particle Swarm Optimization. To test the reliability of the system, SMIB is given the load changes.

\section{a. Frequency Response}

The first process is SMIB frequency analysis. Figure 8 is the frequency response of SMIB, where the disturbance is in the form of a load change of $0.01 \mathrm{pu}$, then after how many seconds a load release of $0.005 \mathrm{pu}$ occurs. In the first response, an increase in load occurs when the electrical power is not equal to the mechanical power $\mathrm{Pe}>\mathrm{Pm}$, resulting in an imbalance between the electrical torque and the mechanical torque. Under these conditions the electrical frequency $(\Delta \mathrm{f})$ will also change. The speed of rotor $(\Delta \omega)$ becomes out of sync during unstable conditions. From the graph, it can be seen that in this condition the frequency moves down before it reaches steady state. The overshoot response shown in table 4.

Table 4. Frequency Deviation

\begin{tabular}{|c|c|}
\hline Deviation & Overshoot (pu) \\
\hline SMIB & $-0.0002386 \mathrm{~s} / \mathrm{d} 0.0001873$ \\
\hline SMIB-PSS & $-0.0002104 \mathrm{~s} / \mathrm{d} 9.915 \mathrm{e}-05$ \\
\hline SMIB-PSS-PSO & $-0.0001678 \mathrm{~s} / \mathrm{d} 3.99 \mathrm{e}-05$ \\
\hline
\end{tabular}

Table 4 shows the SMIB overshoot when there is an additional load. The uncontrolled scheme has overshoot of -0.0002386 to 0.0001873 pu with settling time of 15s. SMIB-PSS scheme has overshoot of 0.0002104 to $9.915 \mathrm{e}-05 \mathrm{pu}$ with settling time of 7 seconds. The PSS-PSO SMIB scheme has an overshoot of -0.0001678 to $3.99 \mathrm{e}-05 \mathrm{pu}$ with a settling time of $4 \mathrm{~s}$. Then a disturbance occurs in the system in the form of a change in load which causes the electrical power $(\mathrm{Pe})$ to change. In this condition the electrical power is not equal to the mechanical power $\mathrm{Pe}<\mathrm{Pm}$, which causes the electrical torque and mechanical torque to become unbalanced. This condition causes the electrical frequency $(\Delta \mathrm{f})$ to also change. Rotor rotation speed $(\Delta \omega)$ becomes out of sync when conditions are unstable. So in this condition, the frequency response on the 
graph moves up before returning to a steady state. In this condition, control is needed to return to steady state condition. In this condition the overshoot is shown in table 5. Figure 8 is a graph of the system's electrical frequency response $(\Delta \mathrm{f})$.

Table 5. Frequency Deviation

\begin{tabular}{|c|c|}
\hline Deviation & Overshoot (pu) \\
\hline SMIB & $-9.299 \mathrm{e}-05 \mathrm{~s} / \mathrm{d} 0.0001198$ \\
\hline SMIB-PSS & $-4.427 \mathrm{e}-05 \mathrm{~s} / \mathrm{d} 0.0001048$ \\
\hline SMIB-PSS-PSO & $-1.978 \mathrm{e}-05 \mathrm{~s} / \mathrm{d} 7.0333 \mathrm{e}-05$ \\
\hline
\end{tabular}

The overshoot on the uncontrolled system is 9.299e-05 to 0.0001198 pu with a settling time of 35 seconds. The SMIB-PSS System Overshoot is $-4.427 \mathrm{e}-$ 05 to $0.0001048 \mathrm{pu}$ with a settling time of 25 seconds. The SMIB-PSS-PSO overshoot is $-1.978 \mathrm{e}-05$ to $7.0333 \mathrm{e}-05 \mathrm{pu}$ with a settling time of $22 \mathrm{~s}$. Table 5 shows the overshoot system when the load changes at 20 seconds.

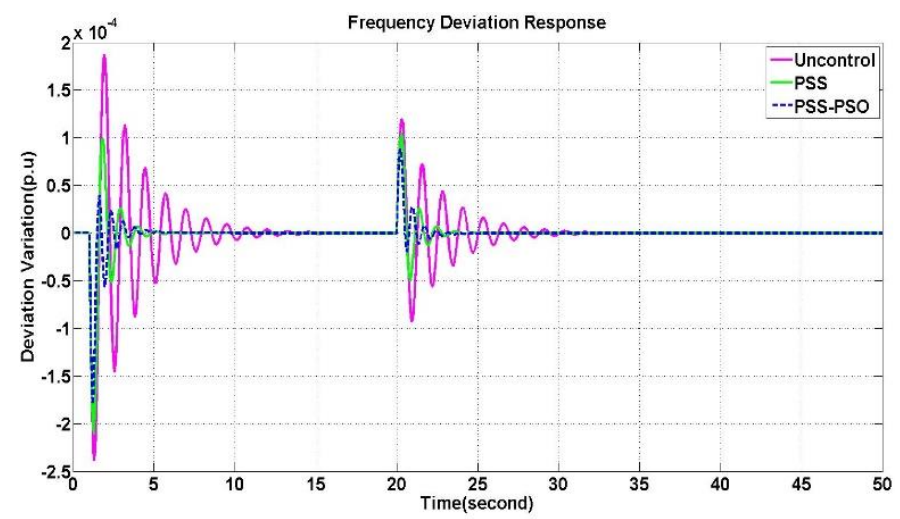

Figure 8. Frequency Response of SMIB

\section{b. Rotor Angle Response}

Next is the analysis of the SMIB rotor angle response with PSS installation. By providing a disturbance in the form of an increase in load of $0.05 \mathrm{pu}$ at $1 \mathrm{~s}$. The increase of load load causes changes in the electrical power to increase. The generator experiences rotor acceleration when the mechanical power of the generator is greater than the electrical power, this will have an impact on the rotor angle, the rotor angle response becomes negative from the conditions before the disturbance, as shown in Figure 8. The rotor angle oscillation is shown in table 6 .
Table 6 . Rotor Angle Deviation

\begin{tabular}{|c|c|}
\hline Deviation & Overshoot (pu) \\
\hline SMIB & -0.03667 \\
\hline SMIB-PSS & -0.0290 \\
\hline SMIB-PSS-PSO & -0.0238 \\
\hline
\end{tabular}

Table 6 is an overshoot of the rotor angle when a disturbance occurs in the form of an additional load. The SMIB scheme without control produces an overshoot of $-0.03667 \mathrm{pu}$ with a settling time of 18 seconds. The SMIB-PSS system has an overshoot of $0.0290 \mathrm{pu}$ with a settling time of $8 \mathrm{~s}$. The SMIB-PSSPSO scheme produces an overshoot of $-0.0238 \mathrm{pu}$ with a settling time of $5 \mathrm{~s}$. The next test is to reduce the load on the SMIB, which causes the generator to experience a slowdown in the rotor because the mechanical power of the generator is smaller than the electrical power. The deceleration of the rotor affects the change in the rotor angle, so that the rotor angle response becomes positive. This is because the magnetic coupling will push the stator field with the rotor field, so that the generator rotor angle will increase, as shown in Figure 9. The system overshoot in this condition is shown in Table 7.

Table 7 is an overshoot of the rotor angle when there is a change in load at 20 seconds. The uncontrolled SMIB has an overshoot of $-0.01652 \mathrm{pu}$ with a turnaround time of 36.8 seconds. The SMIB-PSS scheme has an overshoot of -0.01245 pu with a settling time of 28 seconds. SMIB-PSS-PSO obtained an overshoot of $-0.01162 \mathrm{pu}$ with a settling time of $25 \mathrm{~s}$.

Table 7. Rotor Angle Deviation

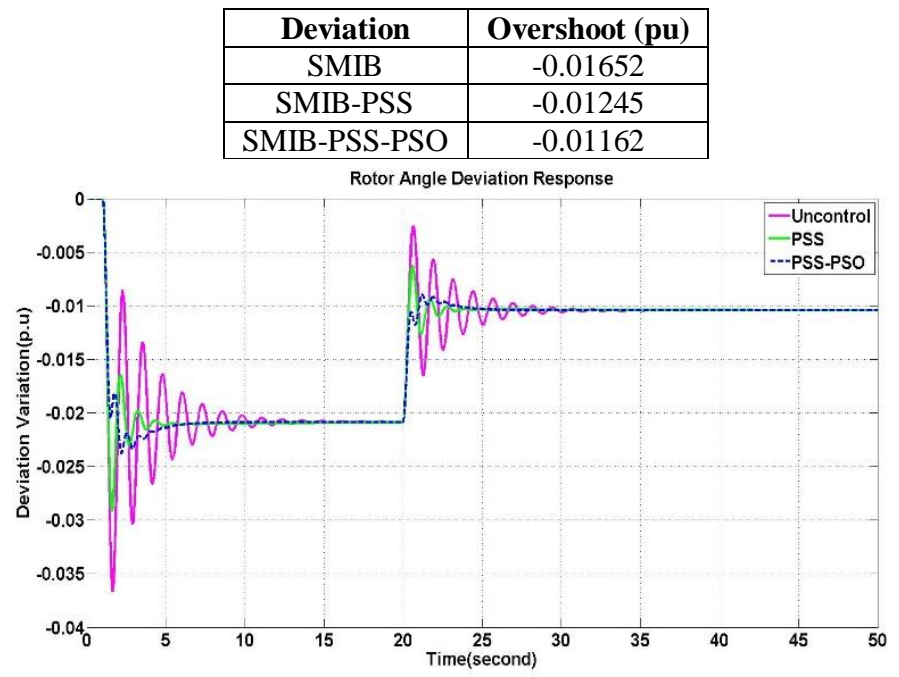

Figure 9. SMIB Rotor Angle Response 


\section{Conclusion}

By tuning the optimal PSS parameters using PSO, the optimal SMIB frequency response is obtained, compared to the uncontrolled scheme, this is indicated by the optimal system frequency response. PSS is able to provide additional damping so that the overshoot oscillations can be damped. With proper optimization of PSS parameters, Overshoot on the system can be reduced..

\section{Acknowledgements}

The authors would like to thank Ministry of Education, Culture, Research and Technology, director general of higher education, Director of Resources of Education, Culture, Research and Technology and Center for Research and Community Service State Polytechnic of Ujung Pandang for supporting the Research

\section{References}

[1] P. Kundur, Power system stability and control.

[2] M. Y. Yunus, M. R. Djalal, and Marhatang, "Optimal Design Power System Stabilizer Using Firefly Algorithm in Interconnected $150 \mathrm{kV}$ Sulselrabar System, Indonesia," International Review of Electrical Engineering (IREE), Vol. 12, No. 3, pp. 250-259, 2017.

[3] M. R. Djalal, M. Y. Yunus, H. Setiadi, and A. U. Krismanto, "SmallSignal-Stability Enhancement using a Power-System Stabilizer based on the Cuckoo-Search Algorithm against Contingency $\mathrm{N}-1$ in the Sulselrabar 150-kV System," Makara Journal of Technology, Vol. 22, No. 1, pp. 1-8, 2018.

[4] M. R. Djalal, A. Imran, and I. Robandi, "Optimal placement and tuning power system stabilizer using Participation Factor and Imperialist Competitive Algorithm in $150 \mathrm{kV}$ South of Sulawesi system," in Intelligent Technology and Its Applications (ISITIA), 2015 International Seminar on, 2015, pp. 147-152: IEEE.
[5] M. R. Djalal, H. Setiadi, D. Lastomo, and M. Y. Yunus, "Modal Analysis and Stability Enhancement of $150 \mathrm{kV}$ Sulselrabar Electrical System using PSS and RFB based on Cuckoo Search Algorithm," International Journal on Electrical Engineering and Informatics, Vol. 9, No. 4, pp. 800-812, 2017.

[6] H. D. Laksono and I. R. Putra, "Analisa Performansi Single Machine Infinite Bus (SMIB) dengan Metoda Linear Quadratic Regulator (LQR)(Studi Kasus: PLTA Singkarak)", (Performance Analysis of Single Machine Infinite Bus (SMIB) with Linear Quadratic Regulator (LQR) Method (Case Study: PLTA Singkarak), Teknika, Vol. 20, No. 2, 2013.

[7] A. M. S. Yunus, M. R. Djalal, and Y. S. Akil, "SMIB stability enhancement using capacitive energy storage and PID based on ant colony optimization," IOP Conference Series: Earth and Environmental Science, vol. 575, p. 012241, 2020/10/29 2020

[8] V. L. A.S.V, R. R. Manyala, and S. K. Mangipudi, "Design of a robust PID-PSS for an uncertain power system with simplified stability conditions," Protection and Control of Modern Power Systems, Vol. 5, No. 1, p. 20, 2020/09/29 2020.

[9] A. Ahmad, "Pengontrolan Sistem Eksiter Untuk Kestabilan Tegangan Di Sistem Single Machine Infinite Bus (SMIB) Menggunakan Metode PID", (Controlling Exciter System For Voltage Stability In Single Machine Infinite Bus (SMIB) System Using PID Method), Jintake, Vol. 5, No. 2, pp. 68-77,, 2014.

[10] L. Chaib, A. Choucha, and S. Arif, "Optimal design and tuning of novel fractional order PID power system stabilizer using a new metaheuristic Bat algorithm," Ain Shams Engineering Journal, Vol. 8, No. 2, pp. 113 125, 2017/06/01/ 2017.

[11] M. Djalal and N. Kadir, "Penalaan Optimal Kontroler PSS-PID Pada Sistem Single Machine Infinite Bus Menggunakan Ant Colony Optimization", (Optimal Tuning of Pss-Pid Controller on Single Machine Infinite Bus System Using Ant Colony Optimization), JST (Jurnal Sains dan Teknologi), Vol. 10, p. 76, 03/24 2021.

[12] I. Robandi, "Modern Power System Control," Penerbit ANDI, Yogyakarta, 2009.

[13] K. R. Padiyar, Power System Dynamics. John Wiley \& sons Ltd, Interlaine Publishing Ltd, 1996.

[14] Suharto, "Penalaan Power System Stabilizer (Pss) untuk Perbaikan Stabilitas Dinamik pada Sistem Tenaga Listrik Menggunakan Bat Algorithm (Ba)", (Tuning Power System Stabilizer (Pss) to Improve Dynamic Stability in Electric Power Systems Using Bat Algorithm (Ba)), Undergraduate, ITS Surabaya, 2015. 